\title{
A Study of Genre Approach in EFL Writing
}

\author{
Chunmei Wang \\ Foreign Languages Faculty, Huaiyin Institute of Technology, Huai'an, China
}

\begin{abstract}
The present study puts SFL-based genre approach under examination for its effectiveness in promoting EFL writers' genre awareness and writing competence in a 16-week semester in a state-run college in the east part of China. Three sets of data from pre- and post-test writings, interviews and questionnaires, are collected and analyzed with the help of the software SPSS and Range 32. The study indicates that the genre approach beats the traditional approach in sensitizing the writers' genre awareness, improving holistic writing quality and enhancing lexical density.
\end{abstract}

Index Terms—genre approach, EFL writing, genre awareness, writing competence

\section{INTRODUCTION}

Writing is a daunting challenge to many a native writer, let alone to those who learn English as a foreign language (EFL), such as Chinese college students. Chinese college students' writings have been reported problematic in some significant ways (Ma, 2002) and the L2 writing instruction and Chinese-specific writing settings are found responsible for the slow progress (Gao, 2007; You, 2004). So what writing approach can better facilitate writings is a question long lingering on the minds of L2 practitioners, educators, instructors and writers. Exigencies exist to examine whether a shift of writing pedagogies can address all or part of the problems mentioned in the above literatures.

The concept genre in the linguistic sense has transformed people's opinions on the nature of writing: writing is longer perceived as static and monolithic; on the contrary, it is dynamic, flexible and social. In line with this new conceptualization, the genre writing approach offers an informing perspective - to write is to communicate and writing is a way of getting things done (Hyland, 2003).

The genre approach, the latest writing approach, takes writing as dominantly linguistic, and it considers context, writer-reader relationship, and purpose at the same time. It also makes a point of practising explicit teaching and providing model texts in L2 classes. In the past two decades, the genre approach draws increasing number of adherents; in the meantime, it is challenged both theoretically and pedagogically. Widdowson (1993) has reservations about genre pedagogy in maintaining that transferable language knowledge cannot be guaranteed to nonnative speakers. Genre pedagogy is accused of impeding “writer's self expression and straight-jacketing learners' creativity through conformity and prescriptivism" (Hyland, 2007, p.152) from the process writing proponents. The reservations about the genre pedagogy point to the necessity of further classroom-based research.

\section{PReVious Literature}

With diverse theoretical grounds and focal points in mind, genre approaches are distilled and posited into three "camps": the Systemic Functional Linguistic (SFL) School, the English for Specific Purposes (ESP) School, and the New Rhetoric (NR) School (Cheng, 2006; Jones, 2011; Hyon, 1996). We work with the SFL line of genre theory, which deems genre as "staged, goal-oriented social process" (Martin, 2009, p.13). The SFL approach draws heavily on the tripartite structure of the language and has stuck to the habit of imparting explicit instructions to learners. Practitioners and researchers in this branch of genre study dedicate themselves to locating the invisible stages in a bulk of discourses and digging the tacit schematic structures out in order to explicate them to learners through the linguistic analysis.

The genre pedagogy in the SFL School, normally presented in a teaching and learning cycle, is characterized by the recycling of three stages: modeling stage, joint negotiation stage, and individual construction stage (Cope \& Kalantzis, 1993). A variety of school genres or curriculum genres, such as report, narrative, argumentation are discussed and their schematic structures are explored in the early classroom application of genre approach. The SFL genre approach exerted a long-lasting impact on the L1 and migrant adult writing in Australia in the $20^{\text {th }}$ century (Hyland, 2005).

A growing body of literatures on the SFL-based genre approach in the EFL classrooms has been reported recently. In Taiwan, 41 English majors work with the SFL-based genre pedagogy in their 10-week summary writing class. Participants are required to summarize their reading of The Adventures of Tom Sawyer into 500 words. The results of the pre-test and post-test writings manifest that the SFL genre approach is effective in L2 writing classes and that students benefit more in aspects of content development and rhetorical organization than in such domains as linguistic accuracy and lexical diversity. It is suggested that greater efforts are still needed to reveal the pros and cons of the genre approach for the purpose of maximizing its effects in L2 writing classrooms (Chen \& Su, 2012). Only one group of learners participates in the aforementioned research and the research instrument is limited to pre- and post tests, which diminish the reliability of the research. 
The other two researches conducted in the EFL college settings greatly illuminate the present research. Yasuda (2011) combines the SFL genre approach with the task-based pedagogy in teaching e-mail writing with 70 Japanese novice undergraduates, and she finds that both the genre awareness and linguistic ability, with the exception to lexical diversity, evidence significant improvement over a 15-week writing course. The defect with her design lies in the fact that there are not two treatment groups to solidify her claim that the improvement is the outcome of the SFL genre pedagogy. In her research, Yayli (2011) incorporates a wide range of genres into her course, namely, e-mail, recipe, CV, letter of complaint and two types of essays when working with the pre-service English teachers in a Turkish university. Genre awareness and cross-genre awareness are reported and discussed and her use of multi-genre portfolios is well worth mentioning. The limitation with her design is that there are a limited number of participants (6 pre-service teachers) in the research and that she fails to investigate participants' linguistic and lexical improvement when examining their genre awareness and cross-genre awareness.

\section{THE STUDY}

The present research brings the SFL-based genre approach into a Chinese college writing classroom to examine whether genre approach can enhance Chinese EFL writers' genre awareness and writing competence, including writing quality, writing fluency and lexical ability, on the part of the learners in the treatment group after 16-week genre instruction. Accordingly, two research questions are formulated as follows:

(1) What are the effects of the SFL-based genre approach on eliciting and developing genre awareness in Chinese college writers?

(2) What are the effects of the SFL-based genre approach on Chinese college writers' writing competence?

\section{A. Course}

Practical English Writing is an optional course in a state polytechnic college in the east part of China. The writing research takes place in the winter semester of the 2012-2013 academic year and the class meets once a week for two sessions, ninety minutes to be exact, for sixteen weeks. At the end of the course two credits are granted to qualified writers.

The writing course incorporates a wide range of genres, such as self-introduction, letters of all sorts of purposes, notes and notices, curriculum vitae and abstracts. The writing syllabus is designed in a continuum from easy to difficult, from daily informal genres to more detached formal ones.

\section{B. Participants}

Two classes of students $(n=32+32)$ are invited to participate in the research and no one quits during the research. Their ages range from 19 to 21 and the percentage of males to females is approximately 1 to 3 in either class. All the subjects are undergraduate non-English majors enrolling in the optional writing class. Class one is randomly set as the control group (CG) and Class two the experiment group (EG).

It has to be acknowledged that the subjects come from two grades, grade two and grade three. Sophomore students are still having compulsory English classes under the title of College English during the research period while the juniors have finished the classroom learning of English, which is required for every undergraduate in their first two years at college.

\section{Instruments}

Both quantitative and qualitative methods are incorporated in the present study, including pre- and post-tests, questionnaire, and interview.

\section{Pre- and Post Tests}

Pre- and post tests are conducted with both the CG $(n=32)$ and the EG $(n=32)$ in class respectively at the beginning and the end of the writing course. All the participants in two classes participate in the written research and no one quits in the process. Time is guaranteed at both tests and no subjects complain about lack of time. What's more, to imitate the real writing situation, there are no limitations set on the length of the two letters.

Pre-test is taken at the first lecture prior to the class instruction and the writings gathered are regarded to reflect the writers' prior writing competence. Post-test is administered at the last lecture upon the completion of the 16-week writing instruction. The 128 copies of writings comprise the written data for the research.

To ensure the comparability of the pre- and post-test writings, the complexity of the two writings is set approximately constant and at each time they are required to writer a letter of apology. The reasons for the choice of a letter of apology are threefold: In the first place, to the best knowledge of the author, the apology letter genre has not been explored in any writing classrooms; in the second place, this genre is a familiar genre to all subjects, therefore they will not be at loss what to write at the pre-test time when pre-test data are first collected; besides, the apology letter genre is a sub-genre of letter writing and is listed on the syllabus of the writing course.

\section{Questionnaire}


The questionnaire is administered with all the 32 subjects in the EG at the last lecture. The reasons are made clear to the students before the distribution of the questionnaire. To ensure the reliability of the questionnaire, subjects are asked to complete the questionnaire in class unanimously and independently.

All the 32 questionnaires are collected after class and they are judged valid for the research. The original questionnaire is printed in Chinese to ensure no misunderstandings arise due to the language barrier.

\section{Interview}

Five interviewees are randomly selected from the EG and the interviewer is the researcher herself. The interview is administered in the researcher's office on a Friday afternoon, a week's later after the post-test has been done. The author interviews the five students respectively at the agreed-upon time and the each interview process is audio taped with the Cool Edit pro software. The subjects are informed in advance that the interview is audio recorded solely for the research purpose and their written permissions are obtained before each interview. The researcher is also authorized to use interviewees' surnames if necessary. After the interview, each interviewee receives a gel pen and a notebook as gifts from the researcher.

\section{Teaching practice}

The teaching practice period lasts from the second week to the fifteenth week. During the in-between 14 weeks, both the $\mathrm{CG}$ and the EG receive writing instructions, finish the same writing assignments, and are both expected to revise according to the feedback. The only difference lies in the teaching methods employed.

For the $\mathrm{CG}$, the traditional writing approach is used throughout the course. At the beginning of the lesson, the lecturer first introduces the kind of writing to be learnt, then provides the model writing, and analyzes the model from the perspective of text structure, development of each paragraph, its lexis and diction of the writing. Some of the commonly-encountered words or sentence patterns are discussed and provided. After the careful studying of the model writing, students are encouraged to imitate a piece of writing according to teacher's requirement. Sometimes class time is set aside for writing and part of writings are collected and corrected in class. Five out-of-class assignments are asked of the learners in the CG. Feedbacks are presented at the very beginning of the next meeting, mainly concerned with such aspects as mistakes in content, structure, and grammar. Therefore, the writing approach employed in the CG can be summarized as the linear way: teacher instruction, model imitation, and student drafting and revising.

For the EG, the SFL-based genre approach guides the whole teaching process. The teaching syllabus in the EG is carefully designed in compliance with the principles outlined in Hyland (2007) and it is strictly observed in the teaching practice. First, needs analysis is taken into consideration in designation of the writing syllabus. It is believed that learners' needs are closely related to their learning motivations and a well-designed teaching schedule can undoubtedly elicit the learners' interest and motivation. All the genres included in this writing course are based on the predictions about the learners' immediate needs and potential needs in the near future. Self-introductions, personal letters, business letters, notices, posters, cover letters, resumes, and abstracts are incorporated in the writing schedule. Second, according to Hyland's (2007) suggestion to "grade genres by perceived increasing levels of difficulty" (p.156), the genres on the learning list are arranged in a continuum from easy genres to demanding ones.

In the teaching phase, both conscious-raising and linguistic developments are two intended objectives. Four stages are identified in the actual writing lessons: context exploration, text exploration, joint construction and individual application. Every genre dealt with in the classroom basically follows the same four-step teaching-learning cycle.

\section{Data collection}

There are 64 subjects participating in the present research. Three sets of data, namely from the pre- and post tests, questionnaire and interview, are collected throughout the 16-week writing research. Questionnaire and interview are only conducted with the 32 subjects in the EG. Questionnaire is administered in class during the last lecture while the interview is conducted a week's later with 5 randomly-selected students in the researcher's office.

Pre- and post test writings are conducted with both groups in class and all copies of writings are collected after class as the written data for the research. On two occasions, 64 subjects are required to write a letter of apology for a particular reason. There are no limitations on writing length and writing time, but all of them finish the letter-writing in class.

Pre- and post-tests are conducted with both CG and EG in class respectively at the beginning and the end of the writing course. All the subjects in two classes participate in the written research and no one quits in the process. Time is guaranteed at both tests and no subjects complain about lack of time. What's more, to imitate the real writing situation, there are no limitations set on the length of the two letters.

\section{Data analysis}

Genre awareness is hardly to be assessed through a set of figures; therefore, it is measured chiefly through qualitative data obtained through questionnaires and quantitative data from the retrospective interviews.

The 128-copy of writings from both the CG and the EG constitute the quantitative data to assess two groups of writers' writing competence. Two experienced college teachers are invited to participate in the research. They are asked to mark each piece of writing twice both holistically and analytically on a five-point scale (5=excellent, 4=good, $3=$ average, $2=$ poor, 1=very poor). Holistic scores are chiefly based on the content, structure and grammar; analytic scores are also marked according to the three analytic criteria based on Lumley's (2005) scale descriptors: task fulfillment and appropriacy (TFA), cohesion and organization (C\&O), and grammatical control (GC). 
The two independent raters agree with each other on most of the scores and the inter-rater reliability is measured as well. Marks are taken down and analyzed with software SPSS 14.0. Results are compared synchronically and diachronically.

\section{RESUltS AND DisCUSSION}

\section{A. Effects on Genre Awareness}

The questionnaire consists of three close-ended questions and one open-ended question. The descriptive statistics of the first three questions is listed in the Table 1.

TABLE 1

DESCRIPTIVE STATISTICS OF THE QUESTIONNAIRE

\begin{tabular}{|c|c|c|c|c|c|c|}
\hline Questions & Mean & SD & Not at all & A little & Somewhat & A lot \\
\hline $\begin{array}{l}\text { 1. To what degree did you have prior experience with } \\
\text { writing English letters before taking this class? }\end{array}$ & 2.576 & .716 & 1 & 15 & 13 & 3 \\
\hline $\begin{array}{l}\text { 2. To what degree do you think you have improved your } \\
\text { ability in writing the genres learned this semester? }\end{array}$ & 3.500 & .568 & 0 & 1 & 14 & 17 \\
\hline $\begin{array}{l}\text { 3. To what degree do you think you have changed your way } \\
\text { of thinking about writing in English? Take letter writing as } \\
\text { an example. }\end{array}$ & 3.094 & .588 & 0 & 4 & 21 & 7 \\
\hline
\end{tabular}

$\mathrm{n}=32$; SD stands for standard deviation. Likert scale values: not at all (1), a little (2), somewhat (3), and a lot (4).

At the end of the questionnaire, an open-ended question encourages all the 32 subjects to reflect on their changed views on writing. The dynamic nature of writing and the prospective usefulness of the genre in the future life are two major contributing factors. Many a subject claims that they perceive new understanding of writing by saying that "writings vary a great deal in the degree of courtesy and formality according to such factors as its potential readers" or that "English writing is more than a 150-word composition that has to be finished within 30 minutes as we usually encounter on test papers."

A retrospective interview is arranged to triangulate and expand the information gained through the questionnaire. In the interview with the 5 randomly-selected students, when the two copies of writing are presented in front of them, they are pressed to comment on the differences and the reasons for the changes, and all of them detect some changes and offer different explanations.

To summarize, most of the participants report progress and enhancement in genre knowledge and genre awareness after the genre instruction but it must be heeded that many learners report their increased genre awareness on the rather surface-level aspects, such as proper salutation and complimentary closure, layout of the letter, and degree of formality in vocabularies.

\section{B. Effects on Writing Competence}

Writing competence here is an umbrella term, which is further deconstructed into three minor aspects related to the L2 writers' writing ability: writing quality, writing fluency and lexical ability.

\section{Effects on Writing Quality}

Holistically speaking, the CG and the EG are at roughly the same level with regard to their overall writing ability at the outset of the study $(t=.295, p=769)$. Thus, the group difference cannot account for the following differences found in the post-test writings; treatment effects lead to the possible differences. Paired samples $t$-test respectively for CG and EG indicate that both groups advance significantly in the semester since the $p$-value in either case is lower than .05, but at a different pace: the EG $(t=-7.0, p=.000)$ outperforms the $\mathrm{CG}(t=-3.80, p=.001)$. Independent samples $t$-test for $\mathrm{CG}$ and EG post-test holistic scores reveal that the difference between the $\mathrm{CG}(\mathrm{M}=3.85, \mathrm{SD}=.69)$ and the $\mathrm{EG}(\mathrm{M}=4.19$, $\mathrm{SD}=.51)$ on holistic scores of the post-test writings are significant $(t=-2.207 ; p=.031<.05)$. That is to say, the SFL-based genre approach is observed to have better effects on improving the writers' overall writing quality.

From the analytic perspective, independent samples $t$-test for CG and EG pre-test analytic scores indicate that $p$-value for TFA, C\&O, and GC is respectively .767, .35, and .868. None of them is below .05, so no statistically significant group difference is found in any of the three aspects.

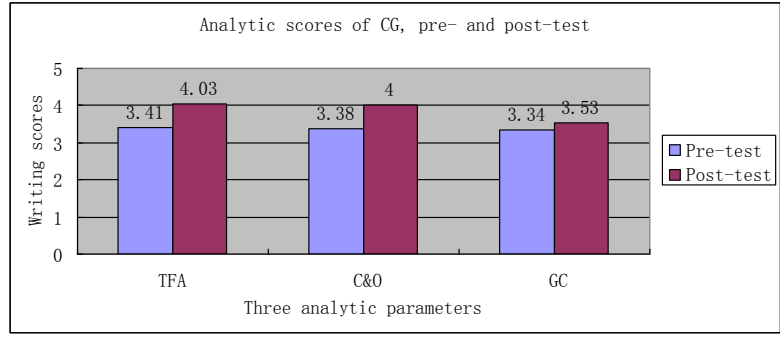

Figure 1 The CG's changes in analytic scores

Notes: TFA=task fulfillment and appropriacy; $\mathrm{C} \& \mathrm{O}=$ cohesion and organization; $\mathrm{GC}=$ grammatical control 
Figure 1 and 2 show how the three analytic aspects evolve after the 16-week instruction in the CG and EG. It can be easily detected that all the three aspects in two groups are hoisted, but with at different pace in two groups with the three parameters. The improvements in TFA and C\&O are comparatively noticeable while the change in GC is negligible.

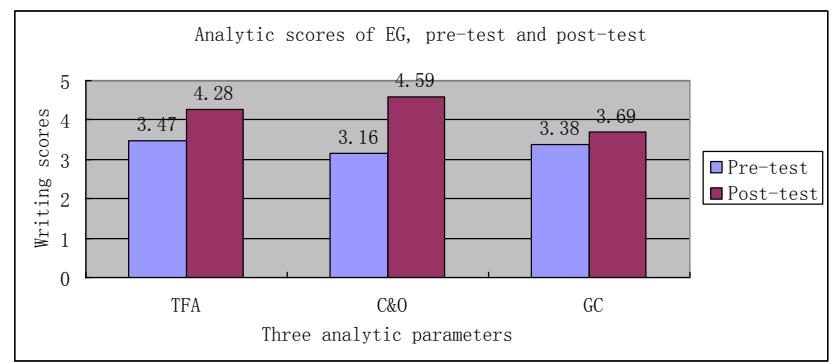

Figure 2 The EG's changes in analytic scores

Notes: TFA=task fulfillment and appropriacy; $\mathrm{C} \& \mathrm{O}=$ cohesion and organization; $\mathrm{GC}=$ grammatical control

Paired sample t-tests CG analytic scores reveal that the CG improves in mean scores in all the three parameters, but the variances between different members in the CG in fact are further widened. Significant differences are found in two parameters: TFA $(t=-3.898 ; p=.000<.05)$ and $\mathrm{C} \& \mathrm{O}(t=-3.056 ; p=.005<.05)$. Although the mean score is slightly improved, the statistically significant difference in GC is not found $(t=-1.099 ; p=.28>.05)$. Similarly, the EG improves in the mean scores of the three parameters (see Fig.2); what is especially worth mentioning is that the EG exhibits signs of convergence in writing quality. This finding is very crucial for the present research.

It can be safely concluded that the developments of the three parameters of writing competence in the present study do not progress concurrently. The exterior problems can be addressed immediately and promptly, such as the format of a letter, the proper complimentary close and how to address a person properly, while the interior problems are hard to detect and to be removed. The diversity in sentence structures and the proper word choice are hard to improve due to the limited course time; they are accumulated in everyday learning and this knowledge is expected to be added to their language repertoire on a long-term basis. The tentative conclusion drawn here is that the SFL genre-approach beats the traditional approach not only in its lifting up the overall writing quality but also in its potential to facilitate a wide variety of writers, including those at the lower levels.

\section{Effects on Writing Fluency}

Brown (1994) refers to fluency activities as "saying or writing a steady flow of language for a short period of time without any self- or other correction at all” (p. 113). Writing fluency in many studies is measured exclusively by writing length or the number of tokens (for example, Yasuda, 2011). The ability to write longer in similar situations is presumed to indicate the writer's improved writing fluency and writing ability. In the present research, in judging writing fluency, we also take writing quality into consideration given that writing length alone cannot speak much about the writers' writing ability.

The 128 copies of writings, if compared synchronically and diachronically, reveal more about writing fluency. Synchronically speaking, the CG participants write more and longer than their counterparts in the EG at the beginning of the semester. For the CG, there are 3385 words in the 32 pieces of writing (numbers included); the mean length of each piece is about 106 words. For the EG, there are altogether 2766 words and the mean length of each writing is 86 words. The independent samples $t$-test reveals there exists marked difference between the CG and the EG in the length of the pre-test writings $(t=2.805 ; p=.007<.05)$. The above-mentioned tendencies persist in the post-test writings. The CG still writes more and longer sentences, and the word choices become even closer. Independent samples $t$-test on the post-test writings of the CG and the EG indicates statistically significant differences between the CG and the EG in the length of the post-test writings are not removed at the end of the course $(t=3.037 ; p=.003<.05)$.

Diachronically speaking, some consistent phenomena are also observed in the two groups. For both the CG and the EG alike, the pre-test writings are longer than the post-test ones, so are the number of sentences and the mean words for each writing; both groups increase their sentence length in the post-test writings. The CG increases one word in sentence length (pre-test $=11.06$, post-test $=12.13$ ) while the EG makes greater gains (pre-test $=9.85$, post-test $=11.93$ ). Paired samples $t$-tests indicate that there are significant differences between the pre-test writings and the post-test writings in the CG $(t=2.377 ; p=.024)$ and the EG $(t=3.395 ; p=.002)$.

Although both the CG and the EG write shorter letters at the post-test, they are awarded better grades. Therefore, it cannot be concluded that their writing fluency and writing ability declines; on the contrary, they write more pertinent letters after the 16-week genre instruction.

3. Effects on Lexical Ability

Lexical ability in terms of lexical diversity and lexical sophistication is under examination respectively through type token ration (TTR) and the distribution of base words in the writings with the help of software Range 32 . Lexical diversity is regarded as an essential indicator of a writer's writing competence and is employed as the most important 
parameters in assessing one's writing (Yu, 2009). In the present research, lexical diversity is measured by TTR in the written production.

Statistics indicate that at the beginning of the semester, as to TTR there is no significant difference between the CG $(\mathrm{Mean}=68.78 \%, \mathrm{SD}=6.828)$ and the $\mathrm{EG}(\mathrm{Mean}=65.63 \%, \mathrm{SD}=7.071)(t=1.816 ; p=.074>.05)$, but at the end of the semester statistically significant differences arise between the $\mathrm{CG}(\mathrm{Mean}=73.16 \%, \mathrm{SD}=7.03)$ and the $\mathrm{EG}(\mathrm{Mean}=$ $76.93 \%, \mathrm{SD}=5.3)(t=-2.435 ; p=.018<.05)$. Marked differences are also observed in the pre- and post-writings in the two groups $(t=-2.474, p=.019<.05$ for CG; $t=-2.264, p=.031<.05$ for EG).

Paired samples $t$-tests on TTRs of CG and EG pre- and post-test writings indicate that both groups make clear gains in terms of TTR $(t=-2.474, p=.019<.05$ for the CG; $t=-2.264, p=.031<.05$ for the EG). A major finding in TTR is that at the beginning of the semester no significant difference is found between the CG and the EG, therefore, the treatment effects are responsible for the marked differences found in TTR at the end of the semester.

Lexical sophistication, also phrased as lexical rareness, chiefly examines the proportion of less frequent or advanced words in a text.

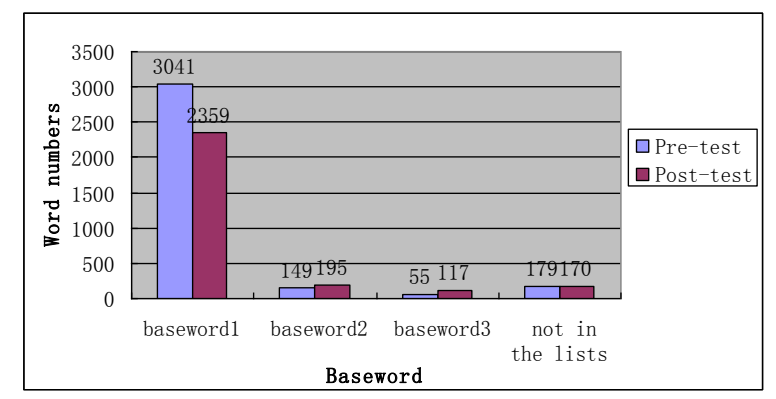

Figure 3 Distribution of basewords for the CG in pre- and post tests

Range 32 categorizes the written material into four groups of basewords. Generally speaking, words in base list one and base list two are high-frequency vocabulary while words in base list three are low-frequency vocabulary. Fig. 3 presents the distribution of basewords in the pre- and post-test of the CG. As the figure shows, compared with the pre-test writing, the post-test writing uses fewer words in baseword1, more words in baseword 2 and baseword3.

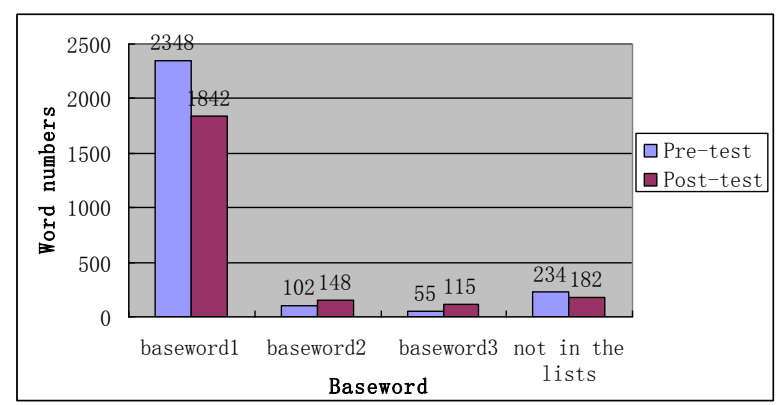

Figure 4 Distribution of basewords for the EG in pre- and post tests

Similar results are also observed in the EG (see Fig. 4). The number of words in baseword1 is observed to decrease to a large extent from 2348 in the pre-test to 1842 in the post-test; more words in baseword 2 and baseword3 are used in the post-test writings, among which the use of words in baseword 3 doubles from 55 in the pre-test to 115 in the post-test.

\section{CONCLUSION AND IMPLICATION}

The present empirical research aims at investigating the effects of the SFL-based genre approach on Chinese college-level L2 learners from two major aspects: genre awareness and writing competence. Two major findings are reported as follows:

Firstly, genre awareness is embedded in learners and their repertoire of genre knowledge is enriched in the SFL-based genre writing class, chiefly by means of explicit teaching. This finding echoes some other researches in EFL contexts (for example, Yayli, 2011; Yasuda, 2011). Explicit instruction advocated in the genre approach shortcuts the process that the L2 learners need to fully understand how a text is constructed through the interaction of purpose, audience and social context and sensitizes them to both the dynamic and stable nature of genre. In the present research, the analysis of qualitative data indicates that the heightened reader-writer relationship and the formal genre knowledge contribute to the noticeable growth in genre awareness.

Secondly, the SFL-based genre writing approach facilitates the development of the writing competence in an enormous way. From the perspective of writing quality, the CG and the EG are of the similar writing level at the outset 
of the research, but after the 16-week genre instruction, the EG achieve statistically significant grades at the post-test in terms of holistic scores and the C\&O aspect of the three analytic scores. What is especially worth mentioning is that the EG not only achieve higher writing scores, the SD in the group is also observed to converge. It manifests that the genre approach benefits a wide range of writers.

As for writing fluency, it is not accompanied by increased writing length. In the present research, both the CG and the EG produce better writings with relatively fewer words. That is to say, writing quality does not always go hand in hand with writing fluency. In addition, mixed results are found with the learners' lexical ability. Significant differences are found with the CG and the EG with regard to lexical diversity while the progress in lexical sophistication is found insignificant. The failure in increasing the learners' lexical sophistication points to the necessity of modifying the genre writing approach to make it better serve the needs of learners at a relatively low level. For advanced learners, there is no urgent need to spend much time on sentence-level language, specifically vocabulary, but for the inexperienced or low-level writers, the necessity is obvious and cannot be ignored.

Two major pedagogical implications are presented based on the findings of the present 16-week genre writing course, which are believed to offer some useful insights into the genre writing approach in L2 contexts.

First, due attention should be paid to the issue of genre awareness development in L2 language classrooms, especially for novice writers who have limited experience with writing in an L2 context. Only part of the genres can be learned in class, learners may encounter new genres in their future work situations, so it is more important to teach them methods of approaching a genre. As the old Chinese saying goes, "delegate to fish, as delegate to fish". In the similar vein, cultivating genre awareness in an L2 learner is of greater importance than investing all time in any particular genre (Johns et al., 2006).

Second, hybrid writing approach can be developed to orient different learners. Genre approach has been employed in different contexts with varying-competence learners, but it does not follow that in all classrooms the genre approach should be applied in the same way; on the contrary, the genre approach should be adapted to accommodate to the needs of diverse learners.

\section{LimitATIONS AND SUGGESTIONS FOR FURTHER RESEARCH}

Limitations of the study should be acknowledged: first, the subjects for the present research are not from the same grade; second, the quantitative results are solely based on the genre of apology letters within a short period of time; third, another important caveat that should be made clear is the researcher's personal experience and ability.

Further researches can be carried out with the above-mentioned limitations in mind. First, a longitudinal research is desired for the observation of continual development in terms of both genre awareness and genre acquisition on the part of the L2 writers. Whether the learners employ the genre awareness and genre knowledge in a writing course to assist their subsequent learning is an area of much interest. Second, further studies are needed to investigate whether the heightened genre awareness derived from the study in a handful of genres is conducive to the development of cross-genre awareness. Third, an interdisciplinary genre research between learners' L1 and L2 is another prosperous research area in genre studies. It has been noticed that quite a few writers draw on their L1 knowledge in drafting their L2 writings, but it is beyond the scope of the present research. Whether or how the L2 writers transfer their genre awareness or genre knowledge developed in the L2 classrooms to their L1 writings is well worth researching.

\section{REFERENCES}

[1] Brown, H. D. (1994). Teaching by Principles: An Interactive Approach to Language Pedagogy. Upper Saddle River, NJ: Prentice Hall.

[2] Cheng, A. (2006). Understanding learners and learning in ESP genre-based writing instruction. English for Specific Purposes, 25, 76-89.

[3] Chen, Y. S., \& Su, S. W. (2012). A genre-based approach to teaching EFL summary writing. ELT Journal, 66(2), 184-192.

[4] Cope, B., \& Kalantzis, M. (Eds.). (1993). The power of literacy: A genre approach to teaching writing. Bristol, PA: Falmer Press.

[5] Gao, J. (2007). Teaching writing in Chinese universities: Finding an eclectic approach. Asian EFL Journal, 20, $285-297$.

[6] Hyland, K. (2003). Second language writing. Cambridge: Cambridge University Press.

[7] Hyland, K. (2005). Teaching and researching writing. Beijing: Foreign Language Teaching and Research Press.

[8] Hyland, K. (2007). Genre pedagogy: Language, literacy and L2 writing instruction. Journal of Second Language Writing, 16, 148-164.

[9] Hyon, S. (1996). Genre in three traditions: Implications for ESL. TESOL Quarterly, 30, 693-722.

[10] Lumley, T. (2005). Assessing second language writing: The rater's perspective. Frankfurt am Main: Peter Lang.

[11] Johns, A. M., Bawarshi, A., Coe, R. M., Hyland, K., Paltridge, B., Reiff, M. J., \& Tardy, C. (2006). Crossing the boundaries of genre studies: Commentaries by experts. Journals of Second Language Writing, 15, 234-249.

[12] Johns, A. M. (2011). The future of genre in L2 writing: Fundamental, but contested, instructional decisions. Journal of Second Language Writing, 20, 56-68.

[13] Ma, G. H. (2002). Contrastive analysis of the linguistic characteristics of the Chinese and American college students' writings. Foreign Language Teaching and Researching, 34, 345-349.

[14] Martin, J. R. (2009). Genre and language learning: A social semiotic perspective. Linguistics and Education, 20, 10-21. 
[15] Widdowson, H. G. (1993). The relevant conditions of language use and learning. In M. Krueger \& F. Ryan (Eds.), Language and content: Discipline and content-based approaches to language study (pp. 27-36). Lexington, MA: D. C. Heath.

[16] Yayli, D. (2011). From genre awareness to cross-genre awareness: A study in an EFL context. Journal of English for Academic Purposes, 10, 1-9.

[17] Yasuda, S. (2011). Genre-based tasks in foreign language writing: Developing writer's genre awareness, linguistic knowledge, and writing competence. Journal of Second Language Writing, 20, 111-133.

[18] You, X. (2004). New directions in EFL writing: A report from China. Journal of Second Language Writing, 13, $253-256$.

Chunmei Wang was born in Huai'an, China, in Feb. 1977. She has just earned her master's degree of English Language and Literature from Jiangsu Normal University and her major interest is EFL writing and teaching pedagogy.

She has worked as an instructor in the Foreign Languages Faculty of Huaiyin Institute of Technology since 2006, chiefly teaching College English to non-English majors. 